Jorge Costadoat, S.J.

Profesor de la Facultad de Teología

Pontificia Universidad Católica de Chile

\title{
La hermenéutica en las teologías contextuales de la liberación
}

Las teologías contextuales pretenden ser teologías hermenéuticas, teologías que invocan la legitimidad de la interpretación situada o, lo que es lo mismo, la necesidad de toda teología de confesar su relatividad histórica y cultural. Las teologías contextuales se han beneficiado del desarrollo de la filosofía hermenéutica y, al hacerlo, han obligado a toda teología a explicitar para qué se interpreta, quién interpreta, qué se interpreta y cómo se interpreta.

Este planteamiento pone de cabeza a la teología tradicional. Cada vez es más difícil una teología universal. Pero, dado que la unidad es un requisito interno de toda ciencia que aspire a la verdad, con mayor razón si la teología pretende ser un discurso sobre el único Dios, las teologías contextuales no pueden eludir el problema de lo "uno y lo múltiple" en su campo específico. Que toda teología sea relativa solo es posible admitirlo en dos sentidos, pero complementarios: como necesidad a priori de una teología local y como obligación de apertura dialéctica a las demás teologías locales. Por esta vía las teologías contextuales triunfan sobre los empeños "fundacionalistas" (idealistas-ideológicos), sorteando a la vez el "relativismo" (postmoderno) que se fragmenta en puntos de vista teológico particulares (1).

Esta vía, sin embargo, clara en principio, importa una ejecución altamente compleja. Desde el momento que se toma en serio la historicidad de la realidad, una vez que se abandona la concepción idealista de su verdad, las teologías contextuales no solo se ven obligadas a relacionarse con la tradición como un conjunto de teologías locales del presente y del pasado, sino también con una realidad histórica y cultural en permanente cambio. En este sentido las teologías contextuales recuperan para la teología su carácter provisional. La verdad de Dios como su objeto más propio, es una realidad que aún está por revelarse hasta el fin de los tiempos. Pero

(1) Cf. David Tracy, “¿Más allá del relativismo y del fundacionalismo? La hermenéutica y el nuevo ecumenismo", Concilium 2/142 (1992) 346. La expresión "fundacionalismo" es engañosa, pues representa el esfuerzo filosófico moderno por superar el "fundamentalismo" que, aun fracasando, impide que este recupere sus pretensiones de verdad. Dice Tracy: "La creencia de los grandes pensadores modernos, desde Descartes hasta Husserl, de que la filosofía es capaz de proporcionar un "fundamento" seguro, cierto, y sin presuposiciones para todo el pensamiento y, en consecuencia, para toda la realidad, es una creencia que se ha venido abajo. Esta tentación peculiarmente moderna -denominada ahora 'fundacionalismo'- está siendo cuestionada en muchas partes. La alternativa, ipor desgracia!, es con harta frecuencia alguna clase de relativismo postmoderno, sea explícito o implícito, sea confiado en sí mismo o modesto”. 
que la revelación histórica de Dios se despliegue en el tiempo y el espacio, complica enormemente cualquier producción teológica que procure ser pertinente.

Siguiendo la clasificación de Robert Schreiter, entendemos aquí que las teologías contextuales son un tipo entre varias posibles teologías locales (2). Y, entre las contextuales, tendremos en cuenta especialmente las "aproximaciones liberadoras", en particular las de la cristología latinoamericana de Jon Sobrino (3) y la cristología feminista crítica de liberación de Elizabeth Schüssler Fiorenza. En el caso de estas teologías se radicaliza la importancia del contexto y de la praxis liberadora para transformar el contexto (4).

La intención de esta ponencia es modesta. Se interesa en describir las características generales de estas teologías de acuerdo a las preguntas hermenéuticas detalladas más arriba. ¿Por qué estas preguntas y no otras? Porque a través de ellas es posible ilustrar mejor acerca de la originalidad de estas teologías respecto de las demás y, a la vez, caer en la cuenta de su problematicidad hermenéutica como se explicará al final.

\section{1. ¿PARA QUÉ INTERPRETAR?}

En estas teologías pueden parecer obscenas sus declaraciones de intenciones. Suponen que toda teología, como toda idea, es "interesada", cumple una función respecto de la realidad histórica. Dice Jon Sobrino: "Todo pensamiento está ubicado en algún lugar y surge de algún interés; tiene una perspectiva, un desde dónde y un hacia dónde, un para qué y un para quién. Pues bien, el desde dónde de este libro (Fe en Jesucristo) es una perspectiva parcial, concreta e interesada: las víctimas de este mundo" (5). E. Schüssler Fiorenza, por su parte, declara que una teología de la liberación crítico-feminista no puede contentarse con "analizar y explicar las estructuras sociorreligiosas de dominación que marginan y explotan a las mujeres y a otras no-personas", sino que procura "cambiar por completo las estructuras de alienación, explotación y exclusión. Su meta es transformar los saberes teóricos y teológicoreligiosos y los sistemas sociopolíticos de dominación y subordinación" (6).

Sea para mantenerla sea para cambiarla, la teología se interesa por la realidad. En la medida que el "desde dónde" sea la realidad de los pobres/mujeres, en cuanto su realidad sea considerada lugar teologal en el que Dios mismo se expresa, las

(2) Cf. Robert Schreiter, Constructing local theologies, Orbis Books, NY, 1993, pp. 12-16.

(3) Se citan aquí las dos obras cristológicas principales de Jon Sobrino, Jesucristo Liberador (JL), Trotta, Madrid, 1991, y La fe en Jesucristo (FJ), Trotta, Madrid, 1999; y el libro de Elizabeth Schüssler Fiorenza, Cristología feminista crítica (CFC), Trotta, Madrid, 2000.

(4) "Los modelos de liberación analizan la experiencia vivida de un pueblo para desenmascarar las fuerzas de opresión, lucha, violencia y poder". Se concentran en los elementos conflictivos que oprimen a una cultura y en extirparlos. "En medio de la pobreza absoluta, la violencia política, la privación de derechos, la discriminación y el hambre, los cristianos se mueven del análisis social al testimonio bíblico para encontrar en estos eco, en orden a comprender la lucha en la que están empeñados o para encontrar dirección para el futuro. Los modelos de liberación se concentran en la necesidad de cambio" (R. Schreiter, o.c., p. 15).

(5) FJ., pp. 14-15.

(6) CFC., p. 30. 
teologías de la liberación aspiran a constituirse en pensamiento capaz de liberar. Pero, además, este objetivo lo cumplen elucidando los déficit de otras teologías que, por no integrar a los pobres/mujeres en su reflexión, resultan para estos irrelevantes o encubridoras de la injusticia que los oprime. Desde la perspectiva de los también llamados "pueblos crucificados", Sobrino denuncia un extravío de la teología: "No llegó (el reino), pero sí llegó el mediador (Jesús), lo cual llevó a que las cristologías se centrasen en la persona de Cristo e ignorasen la causa de Jesús, que es el reino de Dios para los pobres. El reino quedó reducido a la persona de Jesús o a su resurrección. Fue sustituido espuriamente, y a veces pecaminosamente, por la Iglesia. Su destinatario fue universalizado, y los pobres perdieron centralidad histórica y teologal" (7).

La cristología de E. Schüssler Fiorenza, al igual que la de Jon Sobrino, combate la función ideológica de la religión y de la teología. Sin una análisis sistémico global de la cultura y de la religión que despeje el camino a una cristología que impulse una praxis democratizadora, "la religión en general y la cristología en particular seguirán siendo un arma peligrosa en manos de los poderosos, que la usan para fines conservadores y opresores" (8). Un pretendido interés por Dios que no se interese primeramente por la salvación del hombre, es denunciado por estas teologías como una renuncia a la misión de la teología, pues en la consideración teologal de los postergados "la teología se juega su identidad" (9).

La declaración de la "parcialidad", aunque no libra a la teología de la ideología, constituye un primer paso para salir de su trampa. El hecho es que las teologías contextuales de liberación anuncian abiertamente su "desde dónde" y su "hacia dónde". El aparato interpretativo de estas teologías contextuales de liberación tiene por objeto último orientar una lucha transformadora, un cambio político. En particular la cristología de E. Schüssler Fiorenza desea arraigar en las luchas de los diversos grupos feministas de liberación y ponerse a su servicio.

Por lo mismo, las teologías contextuales de liberación son teologías conflictivas. Dan por supuesto que la realidad está en disputa, que hay intereses sociales en conflicto, que la historia no es neutra, que hay que tomar partido a favor de una determinada causa, pues de lo contrario prevalecerá la causa enemiga. Los teólogos procuran involucrarse en una lucha ya existente, dejándose afectar por la resistencia que ella implica y corriendo incluso el riesgo del martirio. El Jesucristo liberador de Jon Sobrino ha terminado de ser redactado después del martirio de su propia comunidad: "Lo hemos escrito en medio de la guerra, de amenazas, de conflictos y persecuciones, que producen innumerables urgencias a las cuales hay que atender e innumerables trastornos en el ritmo de trabajo. El asesinato de mis hermanos jesuitas, de Julio Elba y Celina, dejó el corazón helado y la cabeza vacía" (10). Al entrar en los conflictos sociales, la teología de los teólogos liberacionistas reemplaza la neutralidad afectiva que la actividad intelectual y científica normalmente requiere, por una apasionada toma de postura. Esta los impulsa a pensar y a pensar correctamente (11).

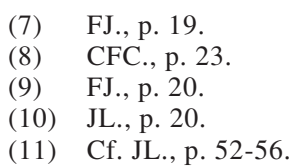


Además de asumir el conflicto social, las teologías contextuales de liberación entran en el conflicto que se da al interior de la Iglesia. No sería posible de otro modo, puesto que lo que sucede en la realidad social, histórica y cultural en perjuicio de los "últimos" se expresa en la Iglesia en la medida que ella, no pudiendo abstraerse de su propia mundanidad, puede inclinarse del lado de los poderosos. "Las luchas por la democracia radical y por la autoridad religioso-teológica de las mujeres están intrínsecamente interrelacionadas" (12). Las teologías no solo representan intereses mundanos, sino intereses en pugna también dentro de la Iglesia. Las teologías, en la misma Iglesia, justifican la dominación o la suprimen. No hay termino medio. Las teologías contextuales de liberación buscan la unidad de la Iglesia en el largo plazo. En lo inmediato, ven necesario combatir teologías, imágenes de Dios, de Cristo o de la Iglesia que privilegian a unos y oprimen a otros. Las teologías contextuales arrancan de lo particular para llegar a lo universal, en contra de las teologías tradicionales que parten de lo universal para llegar a lo particular. En este conflicto, ellas sacan a la luz sus propias motivaciones, encarando y desenmascarando la pretensión ideológica hegemónica de las teologías que no pretenden ser contextuales. E. Schüssler Fiorenza entra en pugna incluso con las teologías feministas que, al reproducir los marcos ocultos de sentido, particularmente el esquema kyriarcal moderno del sexo/género, facilitan una vez más la opresión de las mujeres y los hombres pobres (13). Este es el aporte propio de su Cristología feminista crítica. Porque la unidad social y eclesial en la igualdad, en la justicia y en la paz entre todos los hombres y mujeres constituye el interés soteriológico remoto, la liberación verificada incluso a través del conflicto representa para las teologías de la liberación la tarea próxima y urgente. La salvación escatológica, en consecuencia, se espera como resultado de una reconciliación histórica y religiosa que no tendrá lugar sino a través de una lucha y una confrontación.

(12) CFC., p. 25.

(13) La cristología de E. Schüssler Fiorenza es crítica respecto de las teologías feministas, aun cuando se ubica en su mismo cauce. Para obligarlas a ir todavía más lejos, reemplaza la categoría usual de "patriarcado" por el de "kyriarcado". Si el primero se vincula estrechamente al género masculino del "padre", el segundo alude al abuso del poder que ella combate más allá de toda cuestión de género. Este ha sido tradicionalmente, "el gobierno del emperador/ amo/ señor/ padre/ esposo sobre sus subordinados" (CFC., p. 32). Pero no todos los hombres son explotadores. "A su vez, el término 'kyriocéntrico' se refiere a articulaciones ideológicas que convalidan y son sostenidas por relaciones kyriarcales de dominación. Puesto que el kyriocentrismo reemplaza a la categoría del androcentrismo, la mejor manera de entenderlo es considerarlo como un marco intelectual y una ideología cultural que legitima y es legitimada por estructuras sociales y sistemas de dominación kyriarcales" (CFC., p. 32). Para E. Schüssler Fiorenza el antiguo problema del abuso del poder sobre las mujeres principalmente, pero también sobre los hombres, tiene su expresión moderna en los discursos de todo tipo que suponen la dualidad de los sexos y, tal como incautamente hacen hasta ahora las cristologías feministas, los siguen reproduciendo con su crítica a la condición de varón de Jesús y de su Padre: "El marco de sentido 'oculto' que generalmente rige los discursos cristológicos tanto masculino-mayoritarios como apologético-feministas, es el del sistema kyriarcal moderno de sexo/género. Este marco de sentido teórico y teológico entiende a Jesús ante todo como el Hijo varón Divino, a quien $\mathrm{D}^{* *} \mathrm{~s}$, el Padre, envió a redimirnos de nuestros pecados" (CFC., p. 16). 


\section{2. ¿QUIÉN INTERPRETA?}

Otra de las novedades de las teologías contextuales de liberación es la revisión del sujeto teológico. Si tradicionalmente la teología ha sido una disciplina de especialistas, si hasta ahora la cuestión del "sujeto" teológico no ha sido tema más que en la relación entre el teólogo de profesión y el magisterio eclesiástico, para estas teologías el sujeto primario de la reflexión teológica es una comunidad hermenéutica que comprende a priori lo que ha de interpretar. En estas comunidades la función de los teólogos profesionales es clave, pero subordinada. Son las personas mismas comprometidas en una lucha común, las que en diálogo entre sí, con otros movimientos a veces no cristianos y con la asistencia de los especialistas, levantan sus propias preguntas teológicas y aventuran su respuesta. Para Jon Sobrino, el sujeto teológico por excelencia de la teología de la liberación es la "Iglesia de los pobres". Para E. Schüssler Fiorenza es la "ekklêsia de mujer*s (14)“.

En el caso de las comunidades eclesiales de base latinoamericanas en que la "Iglesia de los pobres" toma cuerpo, los sujetos teológicos pueden ser personas que ni siquiera saben leer y escribir y que, por esto mismo, suelen tener una profunda captación de textos que, en el caso de los Evangelios, parecen haber sido escritos exactamente para ellos. La imagen dominante de esta revolución hermenéutica es la de la Biblia en las manos del pueblo. Que efectivamente los pobres entiendan mejor que otros el sentido de la revelación constituye para estas teologías una convicción fuera de discusión, una especie de privilegio epistemológico tomado por asalto de las mismas fuentes sagradas, las que asegurarían que la Buena Nueva es "nueva" y "buena" para los oprimidos antes que para todos y por igual.

La "ekklesîa de mujer*s" de E. Schüssler Fiorenza es ante todo un espacio contrahegemónico al kyriarcado, en el cual se da una "práctica crítica y una visión de la democracia radical en la sociedad y la religión" (15). Es en este espacio que pueden surgir discursos críticos que cambien los discursos teológicos corrientes y hegemónicos, perjudiciales a las mujeres y a otros que comparten su condición oprimida, mediante la creación de "imágenes cristológicas para el cambio" (16). La "ekklesîa de mujer*s" no excluye a los hombres ni se reduce a una comunidad de teólogas. Afirma la autora: "propongo que dentro de la lógica y la retórica de la democracia radical podemos conceptualizar la ekklesîa de mujer*s como el espacio metafórico que puede sostener prácticas críticas de lucha para transformar los discursos institucionales patriarcales sociales y religiosos" (17). La teología de la libe-

(14) El traductor de CFC al castellano ha usado las expresiones de "muj*r" y "mujer*s" para ser fiel al énfasis inclusivo que E. Schüssler Fiorenza da a la expresión "wo/man” y "wo/men” toda vez que, según sus palabras, de esta manera "quiere llamar la atención de los lectores sobre el hecho de que aquellas estructuras kyriarcales que determinan las vidas y el estatus de las mujeres también tienen un impacto sobre los hombres de las razas, las clases, los países y las religiones subordinados, aunque de manera diferente. Por ende, la ortografía wolmen trata de comunicar que, cada vez que hablo de wo/men, no solamente quiero incluir a todas las mujeres sino también a los varones oprimidos y marginalizados. Consiguientemente, wo/men debe entenderse como expresión inclusiva antes que como un término de género exclusivo universalizado" (CFC., p. 15).

(15) CFC., p. 47.

(16) CFC., p. 50.

(17) CFC., p. 51-52. 
ración feminista crítica "se ubica explícitamente dentro de las luchas históricoreligiosas particulares de mujeres contra los sistemas de opresión, que operan en los ejes de clase, raza, género, etnicidad, religión y preferencia sexual, entre otros. Las luchas históricas de carácter político-religioso para cambiar las estructuras explotadoras del kyriarcado -y no la diferencia sexual- constituyen el 'umbral cualitativo' de las articulaciones cristológicas feministas en la ekklesîa de mujer*s" (18).

Las teologías contextuales de liberación no prescinden, sin embargo, del servicio de los teólogos profesionales. Lo requieren, pero por coherencia con sus propios postulados estos teólogos se plantean la pregunta: “¿podemos los no-víctimas hacer teología cristiana desde la perspectiva de las víctimas?" (19). Jon Sobrino confía en que es posible un cierto "entrelazamiento de horizontes" entre la fe de las víctimas y los teólogos de profesión. "En la solidaridad con las víctimas, en el llevarse mutuamente en la fe, se abren los ojos de las no-víctimas para ver las cosas de diferente manera. Que esa nueva visión coincida a cabalidad con la de las víctimas es algo que, pienso yo, nunca llegaremos a saber del todo" (20). En cualquier caso, Sobrino está convencido de que la perspectiva de los pobres aporta luz al tratamiento de los objetos propios de la teología: Dios, Cristo, la gracia, el pecado, etc. "La perspectiva de las víctimas ayuda a leer los textos cristológicos y a conocer mejor a Jesucristo. Por otra parte, ese Jesucristo así conocido ayuda a conocer mejor a las víctimas y, sobre todo, a trabajar en su defensa" (21). Estas teologías alcanzan su estatuto científico propio en la medida que los especialistas elevan a concepto el quehacer teórico y práctico de la comunidad hermenéutica a la que pertenecen.

E. Schüssler Fiorenza concibe a la teóloga feminista como una "agitadora", en otras palabras, "como una extranjera con residencia permanente, que constantemente busca desestabilizar los centros, tanto el ethos pretendidamente libre de valores y neutral de la academia, como la postura dogmática autoritaria de la religión patriarcal” (22). A ella corresponde poner su teología al centro del trabajo teológico. Para que esto suceda, las teólogas feministas "deben permanecer firmemente enraizadas en los diversos movimientos de mujeres que buscan el cambio" (23). Su ubicación simultánea en los movimientos liberacionistas sociales y eclesiales, les permite hablar como "extranjeras con residencia permanente en la Iglesia y la academia" (24). Porque si las teólogas se manejan en los discursos de la universidad, la religión organizada, la teoría feminista y el movimiento feminista, pueden transformar estos discursos en la medida que dan prioridad al movimiento feminista.

En el caso de ambas cristologías, el conflicto por la interpretación de la Sagrada Escritura y de la Tradición se agudiza, con consecuencias para la comunión en la Iglesia. Dado que la "Iglesia de los pobres" arraiga en el "mundo de los pobres" mucho más amplio que la Iglesia, puesto que a este "mundo de los pobres" la

$\begin{array}{ll}\text { (18) } & \text { CFC., p. } 55 . \\ (19) & \text { FJ., p. } 19 . \\ (20) & \text { FJ., p. } 20 . \\ (21) & \text { FJ., p. } 20 . \\ (22) & \text { CFC., pp. } 27-28 . \\ (23) & \text { CFC., p. } 28 . \\ (24) & \text { CFC., p. } 28\end{array}$


teología de la liberación le reconoce el valor de "lugar teologal" en el que Dios actúa y se revela, las tensiones y conflictos sociales son importados al interior de una Iglesia a la que también pertenecen los que no son pobres. Algo muy parecido podrá decirse de la ekklesîa de mujer*s en la medida que, en cuanto comunidad hermenéutica, admite el influjo de movimientos con los que comparte el leitmotiv de la liberación. En tanto la liberación constituye en lo inmediato un valor superior a la comunión, estas teologías contextuales de liberación tienden a enfrentarse espontáneamente con la religiosidad popular y con la jerarquía eclesiástica.

Es conocido el caso de la pugna entre la teología de la liberación y la religiosidad popular en América Latina. Si bien la tendencia a recuperar el valor liberador de la religiosidad popular no carece de representantes valiosos en la teología argentina (como por ejemplo, Juan Carlos Scannone), desde Juan Luis Segundo en adelante la empresa ilustrada de la teología de la liberación, especialmente Jon Sobrino, denuncia el carácter alienante de la fe tradicional y popular en Cristo (25). Que el conflicto teológico haya pasado a las comunidades como iconoclastia y como resistencia a la misma, no sorprende tanto como que la teología de la liberación no haya sabido reconocer el valor hermenéutico de la piedad popular (26). Las últimas transformaciones de la religiosidad latinoamericana, empero, auguran la escritura de obras como la de Pedro Trigo, mucho más finas en el respeto del valor hermenéutico de los mismos creyentes en la diversidad de su realidad (27). Pero también es cierto que la multiplicación de las vías de acceso a Dios menoscaba la pretensión de liberación política de la teología latinoamericana.

En el caso de la teología de E. Schüssler Fiorenza, cabe destacarse que en su afán crítico lleva el conflicto al círculo académico tradicional pero también a la misma comunidad feminista, toda vez que denuncia en las teologías feministas la reproducción de los marcos de sentido oculto que oprimen a las mujeres, cuando adoptan ingenuamente el paradigma moderno de sexo/género, proponiéndose como lucha de las mujeres contra los hombres, en vez de desmantelar las posibilidades estructurales kyriarcales de la opresión social y religiosa en general.

Por último, lo que estas teologías contextuales de liberación no logran resolver bien, es la relación de las comunidades de liberación con la jerarquía eclesiástica, especialmente a propósito del reconocimiento debido a la interpretación auténtica del Evangelio. La crítica a veces virulenta contra el Magisterio eclesiástico no constituye más que la tonalidad emocional de una tensión legítimamente irreductible. Siempre es posible una crítica menos agresiva. Aquello que realmente resulta problemático, es que estas teologías subordinan la unidad de la Iglesia al imperativo de la liberación.

(25) Cf. JL., pp. 25-33.

(26) Cf. Jorge Costadoat, "Interrogantes sobre la cristología latinoamericana", en Jesucristo, prototipo de humanidad en América Latina (Tercera reunión de la Comisión Teológica de la Compañía de Jesús en América Latina), México, 2001, pp. 77-84.

(27) Cf. Pedro Trigo, En el mercado de Dios, un Dios más allá del mercado, Sal Terrae, Santander, 2003. 


\section{3. ¿QUÉ SE INTERPRETA?}

Otro punto de ruptura con la hermenéutica teológica tradicional de las teologías contextuales de liberación atañe al objeto de interpretación. Estas teologías pretenden interpretar una praxis determinada de liberación. Este es su objeto específico.

Puede mover a engaño pensar que el objeto de la cristología de Jon Sobrino sea el Jesús histórico, incluso cuando no se descarte que también lo sea el Cristo proclamado por la Iglesia. Para marcar la diferencia, habría que decir que, en sentido estricto, el objeto de su cristología no es Jesucristo sino el seguimiento de Jesucristo. Si el punto de partida metodológico de esta cristología es el estudio del Jesús histórico, su punto de partida real es la fe en Cristo entendida como seguimiento de Cristo (28). Es la praxis de liberación cristiana la que precede e impulsa la cristología de Jon Sobrino y, ulteriormente, la que se beneficia de esta. Lo que en definitiva interesa es la transformación liberadora de la realidad y la alabanza de Dios por su consecución. De aquí que, al abordar el estudio de Jesucristo, parezca que Jon Sobrino fuerce los datos en función de la liberación. El seguimiento de Cristo conduce e incide en la investigación histórica sobre Jesús y, al hacerlo, redescubre al Cristo de la fe de la Iglesia como un Cristo liberador (29).

Pero si la cristología está al servicio de la cristopraxis y no al revés, no es menor la ayuda que esta presta a aquella. Para Jon Sobrino la cristopraxis perfecciona la cristología, pues "conocer a Cristo es, en último término, seguir a Cristo" (30).

De modo semejante, para E. Schüssler Fiorenza lo fundamental es iluminar la praxis de liberación en la que arraiga su teología: "una teología de la liberación crítico-feminista no arranca de la psicología establecida, la religión popular o la dogmática, sino que comienza con una reflexión feminista sobre las experiencias particulares de mujeres" (31). Aquello que en definitiva interesa se ubica fuera del campo tradicional de la teología. La teología feminista "se comprende a sí misma como una teología de la liberación crítica porque sus análisis sistémicos críticos y sus prácticas intelectuales para la producción del saber religioso buscan apoyar las luchas por la liberación de mujer*s en todo el mundo" (32).

Solo en este sentido, así como Jon Sobrino subordina la cristología al seguimiento de Cristo, la cristología feminista crítica de E. Schüssler Fiorenza se centra en la praxis de Jesús. Pero, a diferencia de las demás cristologías feministas, esta opción le permite, además, escapar al marco oculto de sentido de la diversidad de sexos que sus pares reproducen al quedar fijadas en la condición de varón de Jesús: "a diferencia de las feministas postcristianas y las feministas de género cristianas que presuponen una diferencia esencial o natural de género entre las mujeres y los hombres, las teólogas feministas de la liberación afirman que lo importante teológicamente es la práctica histórica y la humanidad de Jesús, no su condición de varón. La práctica de Jesús como profeta galileo que trató de renovar la esperanza judía del

(28) Cf. Jorge Costadoat, S.J., "La liberación en la cristología de Jon Sobrino", Teología y Vida, Vol XLIV (2003), 62-84.

(29) Cf. JL., p. 59

(30) JL., p. 57.

(31) CFC., p. 250.

(32) CFC., p. 30. 
reino de $\mathrm{D}^{* *}$ s (33), su solidaridad con los pobres y los despreciados, su llamada a un discipulado de servicio voluntario, su ejecución, muerte y resurrección... es lo significativo... Lo importante no es la masculinidad de Jesús, sino su opción por los pobres y su solidaridad con los marginalizados" (34).

¿Qué hay que interpretar? La Sagrada Escritura y la Tradición de la Iglesia, en una palabra la revelación, pero en vista a interpretar una praxis liberadora determinada y bajo el supuesto de que Dios continúa actuando e indicando su voluntad en la historia. Dicho de otra forma. Si el objeto de toda teología es Dios, en el caso de las teologías contextuales de liberación interesa lo que Dios sea "para nosotros" y no lo que Dios sea "en sî". O, mejor, el discurso sobre Dios "en sî" tiene una relevancia subordinada a lo que Dios sea "para nosotros". Esto es, en definitiva, lo único que importa. El objeto de las teologías contextuales de liberación es Dios en su dimensión escatológica y soteriológica, es Dios actuante en la historia como su liberador.

Se argumentará en contrario que la teología tradicional cuando discurre sobre Dios "en sí" también tiene por objeto cambiar la realidad, es decir, sacar las consecuencias de lo que Dios es "para nosotros". Las teologías contextuales de liberación contraatacarán el verticalismo de aquella, en tanto Dios no puede ser "para nosotros", si no es primero Dios "en nosotros" y "con nosotros", la condición de posibilidad de la libertad humana que lo experimenta y lo piensa en una historia que precedió los textos sagrados y que aún no acaba. El objeto teológico de las teologías contextuales de liberación no es simplemente el Dios revelado en los "textos" sino primariamente en el "contexto", pues incluso la Sagrada Escritura es relato, es interpretación de acontecimientos históricos. De aquí que Gustavo Gutiérrez sostenga que lo fundamental del cristianismo consista en "practicar a Dios". Solo en esta perspectiva parece posible recuperar el valor normativo de la Biblia y de la Tradición.

Subyace a este conflicto un concepto distinto de la verdad de Dios como objeto propio de la teología. Las teologías contextuales de liberación acusan a la teología tradicional de querer aplicar la verdad teológica a la realidad histórica, naturalizando y teologizando lo que no ha sido sino producto cultural de la libertad humana en el pasado y, en el presente, alienando a los cristianos de la obligación de orientarse según la voluntad de un Dios vivo que no se cansa de apelar a la libertad de los creyentes para seguir conduciendo la historia hasta sí mismo. Para la teología de la liberación latinoamericana la verdad de Dios es "amor". Por ello prefiere definirse no como intellectus fidei, sino como intellectus amoris (35). Y si no descarta ser intellectus fidei, pone la fides quae al servicio de la fides qua. Así se entiende la afirmación, en cierto sentido provocadora de Gustavo Gutiérrez: "nuestra metodología es nuestra espiritualidad" (36).

Cabe preguntarse si, en el fondo, las teologías contextuales de liberación no tienen un concepto radicalmente distinto de Dios. Ellas no solo no se preguntan por la existencia o no existencia de Dios, sino que parece que no podrían tener al

(33) E. Schüssler Fiorenza sustituye "D-s" (G-d) por "D**s, en atención a la queja de las feministas judías que le reprocharon el contenido conservador de "D-S".

(34) CFC., p. 79.

(35) Cf. JL., p. 55.

(36) Gustavo Gutiérrez, La densidad del presente, Sígueme, Salamanca, 2003, p. 108. 
ateísmo como su referente histórico-teológico último. Para estas teologías, la existencia de un Dios liberador es un presupuesto absoluto. Si la liberación buscada toma cuerpo en la historia, si a través suyo Dios se revela como un "Dios de la vida", un "Dios de las víctimas", por importante que sea esta revelación para combatir el ateísmo contemporáneo ella no constituye el objetivo primero ni principal, sino su virtud liberadora por sí misma. E. Schüssler Fiorenza acoge plenamente el planteamiento típico de la teología de la liberación latinoamericana, cuando afirma que "las teologías de la liberación feministas trasladan su enfoque de la pregunta moderna ‘Cómo podemos creer en D**s?' a las preguntas ‘QQué clase de Dios proclaman los cristianos?'” (37). En la medida que estas teologías deben combatir una noción de Dios que bloquea las posibilidades de liberación de los pobres y las mujeres, su objeto propio parece ser un Dios diferente, uno más preocupado de la injusticia que de la secularización. Esto explica, en parte, que las teologías contextuales de liberación suelan denunciar la falsa neutralidad de la teología académica. Estas teologías detectan una callada connivencia entre la teología académica y la ideología. La imposibilidad de una neutralidad y la posibilidad real de la idolatría al interior de la misma teología, ha sugerido que en América Latina la cuestión de Dios sea tratada bajo el título de "la guerra de los dioses" (38).

Las teologías contextuales de liberación invocan una ruptura epistemológica que, si tiene sólidos antecedentes bíblicos, se apoya además en la moderna filosofía de la praxis. Sin dejar de importar el conocimiento de la realidad de Dios al modo de las filosofías de la naturaleza y del sujeto, el conocimiento teológico tradicional es modificado radicalmente en la medida que se reconoce anterioridad y superioridad epistemológica a la praxis histórica (39). Para las teologías contextuales la praxis no solo depende de una teoría, sino que además constituye su material epistemológico decisivo. En esta nueva óptica, la realidad es fundamentalmente "obra", un producto de la acción. Si se trata de cambiar una realidad histórica, la pretensión de perennidad de la antigua filosofía de la naturaleza o de la moderna filosofía del sujeto, representan una traba. La filosofía de la praxis reclama un conocimiento histórico en sentido estricto, a saber, uno cuya fidelidad a una realidad en permanente cambio no puede sino cambiarla a ella misma.

Teológicamente hablando, las teologías contextuales de liberación suponen que aquello que hay que conocer para transformar es la historia como obra de Dios y como respuesta del hombre. La historia es el ámbito de la acción, y por ende, de la revelación de Dios. Dios no es trascendente a la historia, sino "en la historia". Dios es salvador histórico o Dios no interesa y, en el peor de los casos, una imagen idolátrica suya favorece la opresión. Dios es el Dios de los pobres, el Dios de las víctimas, el Dios que puede reivindicar a los miserables, a los indígenas, a las mujeres, a cualquier minoría que padezca opresión. Evidentemente que la reducción de Dios a su utilidad puede forzar la realidad. Las teologías contextuales de liberación son conscientes de este riesgo. Pero es interesante notar que al

(37) CFC., p. 51.

(38) Cf. Pablo Richard (ed.). La lucha de los dioses, San José, 1980.

(39) Cf. Antonio González, "Primado de la praxis", en Trinidad y liberación, UCA Editores, 1994, pp. 58-63. 
plantearse como teologías de la praxis liberadora se ofrecen a sí mismas como alternativa a las teologías de la naturaleza y de la modernidad que, con su irrelevancia para los oprimidos hombres y mujeres, no terminan de potenciar el ateísmo contemporáneo. Ellas, en cambio, al pretender verificar en la historia sus postulados teológicos se desentienden de la necesidad meramente especulativa de verificarlos en el escritorio.

\section{4. ¿CÓMO SE INTERPRETA?}

Las teologías contextuales de liberación establecen una circularidad hermenéutica entre el "texto" y el "contexto", entre la fides quae y las fides qua, entre la noción de Dios "en sí" y la experiencia de Dios "en y para nosotros".

La praxis se esclarece en la medida que, comandada por lectura de los textos que pueden inspirarla, recurre por otra parte al análisis que las ciencias hacen del contexto en que aquella se inscribe. El socorro de las ciencias sociales hizo famosa a la teología de la liberación a la vez que, la falta de análisis suficientemente sólidos de la realidad socioeconómica de los últimos veinte años, la ha confinado al ámbito de la espiritualidad. Probablemente ha sido esta falencia la que ha hecho cauto a Jon Sobrino al momento de valorar el aporte del análisis social para la teología ${ }^{40}$. E. Schüssler Fiorenza, en cambio, aún invoca la importancia decisiva del análisis sistémico de la dominación (41).

En adelante centramos la atención en la lectura de los textos fundamentales, que en el caso de las teologías contextuales de liberación se realiza bajo el influjo de los intereses específicos de la praxis. Hasta aquí ha debido quedar claro que no es evidente que estas teologías reconozcan un valor normativo a aquellos textos, en el sentido de que las teologías contextuales de liberación subordinan el valor de estos textos a su virtud liberadora. Pero ¿pudiera consistir en otra cosa la hermenéutica? ¿No le corresponde a la hermenéutica exactamente posibilitar la interpretación liberadora o creativa de textos de suyo muertos?

\section{a) El seguimiento de Cristo como principio epistemológico en Jon Sobrino}

En el caso de Jon Sobrino, el texto sagrado tiene un enorme valor para establecer qué se entiende por Cristo liberador. Frente a las imágenes alienantes de Cristo predominantes en la fe de los latinoamericanos, frente a la reducción de esta fe a un "Cristo sin Jesús" (42), todo su empeño se concentra en ilustrar qué ha de entender por Cristo de acuerdo a la enseñanza del Nuevo Testamento sobre Jesús de Nazaret. Lo interesante, aquí, es cómo Jon Sobrino accede a Jesús.

En primer lugar, llama la atención que la hermenéutica de Jon Sobrino se apoya en la recuperación de la historia de Jesús que el mismo Nuevo Testamento realiza cuando, a instancias de la fe de las primeras comunidades cristianas, recupe-

(40) Cf. JL., p. 52.

(41) Cf. CFC., pp. 29-38.

(42) Cf. JL., p. 30. 
ra la historia de Jesús para reivindicarlo como evangelio auténtico y actual. Los evangelistas debieron contar la historia de Jesús, pues de lo contrario las comunidades que vivían de Cristo resucitado habrían terminado por perder su significado soteriológico. Los evangelios son "buena noticia” porque Jesús fue "así”. Fe e historia se requieren dialécticamente: "la respuesta de los evangelios va en una doble dirección: es cierto que no se puede historizar a Jesús sin teologizarlo, pero también es cierto -y en esto está lo específico de los evangelios- que no se puede teologizar a Jesús sin historizarlo" (43).

La cristología latinoamericana, queriendo ser evangelio para los pobres de hoy, también teologiza a Jesús "historizándolo", narrando su historia. Frente a la pregunta típica: ¿qué es posible saber de Jesús de Nazaret?, la cristología latinoamericana afirma no desconocer la problemática y recoge los resultados de la crítica histórica. No deduce criterios apriorísticos de autenticidad, pero a posteriori, a partir de la semejanza entre la historia de Jesús y la actual, confirma lo histórico de Jesús en la línea de la verosimilitud. Desde la realidad latinoamericana, la cristología infiere que Jesús debió ser y actuar de determinada manera y no de otra.

Para Jon Sobrino, lo "evangélico" de la cristología latinoamericana se juega en la circularidad hermenéutica entre las comunidades creyentes y Jesús de Nazaret: "de los evangelios, la cristología latinoamericana aprende... dos lecciones importantes. La primera es que no se puede teologizar la figura de Jesús sin historizarla, narrando su vida y su destino. Sin ello, la fe no tiene historia. La segunda es que no se puede historizar a Jesús sin teologizarlo como buena noticia, y así, en referencia esencial a las comunidades. Sin ello, la historia no tiene fe" (44). La recuperación de la historia de Jesús se pone al servicio de la actualización del significado soteriológico de Cristo en el presente. A este efecto, Jon Sobrino distingue al Cristo que recibimos del pasado del Cristo presente hoy en la realidad de América Latina. "La cristología, para abordar a su objeto Jesucristo, debe tener en cuenta dos cosas fundamentales. La primera, y más obvia, es lo que el pasado nos ha entregado acerca de él, es decir, textos en los cuales ha quedado expresada la revelación; la segunda, menos tenida en cuenta, es la realidad de Cristo en el presente, es decir, su presencia actual en la historia a la cual corresponde la fe real en Cristo" (45).

No basta, en consecuencia, admitir que las fuentes de la cristología consisten en la revelación de Dios trasmitida con la autoridad del Magisterio, y aplicar tales conocimientos a situaciones determinadas. La cristología latinoamericana comprende la historia de Jesús a partir de la fe actual en Cristo de modo que, dado su "lugar" particular, descubre en aquella historia aspectos nuevos y hasta ahora ocultos (46). Que Cristo está presente ya a través de su cuerpo en la historia y como su Señor, es de suyo un dato revelado, pero sobre todo constituye una clave de intelección fundamental de la misma revelación (47).

(43) JL., p. 88.

(44) JL., p. 92.

(45) JL., p. 41.

(46) Cf. JL., p. 42.

(47) Cf. JL., p. 43. 
La recuperación de Jesús de Nazaret, por otra parte, hace las veces de hermenéutica de la sospecha. Jesús es salvaguarda del Cristo. La experiencia latinoamericana enseña que siempre se corre el riesgo de "confesar a un Cristo que no se parece a Jesús, incluso que es contrario a Jesús" (48). La manipulación de su figura es frecuente. Hay que ser conscientes de que también en cristología cabe la posibilidad de la hybris y el pecado. "En nuestra opinión, afirma Sobrino, la posibilidad está dada en que el análisis cristológico tiene que diferenciar a Jesús y al Cristo, y la actuación de la hybris y de la pecaminosidad específicas consiste en determinar de antemano qué sea el Cristo con independencia de lo que fue Jesús. Se presuponen conceptos que, precisamente, desde Jesús no se pueden presuponer: qué es ser Dios y qué es ser humano" (49). La cristología exige una "conversión" a lo que Jesús sea y revele de Dios y del hombre, de lo contrario Jesús no sería el revelador. Esto explica que "el proceder metodológico más operativo es ver a Cristo, en un primer momento, desde Jesús y no a la inversa" (50).

En segundo lugar, Jon Sobrino se ve obligado a aclarar y definir qué entiende por búsqueda del Jesús histórico: “por 'Jesús histórico' entendemos la vida de Jesús de Nazaret, sus palabras y hechos, su actividad y su praxis, sus actitudes y su espíritu, su destino de cruz (y de resurrección). En otras palabras, y dicho sistemáticamente, la historia de Jesús" (51). Desde la perspectiva de la liberación y buscando los principios sistemáticos que le permitirán articular mejor su cristología, va todavía más lejos, hasta preguntarse: ¿qué es lo "más histórico" de la historia de Jesús? (52). Él mismo responde: "nuestra tesis es que lo más histórico del Jesús histórico es su práctica y el espíritu con que la llevó a cabo" (53). Lo histórico es lo que Jesús hizo por el reino de Dios, con el objeto de que se siguiera haciendo. Sobrino busca en los textos de la Escritura aquella práctica de Jesús que nos fue contada como una historia que debía proseguirse.

Se advierte aquí como Jon Sobrino supera las antiguas aproximaciones liberales a la Escritura, pero también a autores como Kähler y Bultmann. Lo histórico de Jesús fundamenta el keryma, siendo el kerygma en definitiva lo que importa. "Lo histórico de Jesús no significa... desde un punto de vista formal, aquello que es simplemente datable en el espacio y en el tiempo, sino lo que nos es transmitido como encargo para seguir transmitiéndolo" (54). Si la Escritura da cuenta de una praxis histórica de Jesús que debe continuarse a futuro, la fe cristiana debe articularse como pro-seguimiento de Cristo. Jon Sobrino reconoce que hacer de la praxis de Jesús lo más histórico suyo constituye una opción. Siempre es una opción hermenéutica reconocer o no que tal praxis deba convertir este mundo en reino de Dios.

Ante la acusación hecha a Jon Sobrino de reducir a Jesús a un "símbolo práxico", este contraataca afirmando que su cristología no solo no abandona a la persona de Jesús, sino que desde la perspectiva de la praxis la recupera. Para la cristología
(48) JL., p. 62.
(49) JL., p. 63.
(50) JL., p. 63.
(51) JL., p. 76.
(52) Cf. JL., p. 76.
(53) JL., p. 77.
(54) JL., p. 77. 
latinoamericana, Jesús es norma normans, non normata: "hay que remontarse a la práctica de Jesús, porque es la de Jesús" (55). Pero, además, desde la praxis de Jesús es posible conocer mejor la persona de Jesús: "pensamos que se accede mejor a lo interno de Jesús (la historicidad de su subjetividad) desde lo externo de su práctica (su hacer historia), que a la inversa" (56).

En fin, si el punto de partida real de la cristología es siempre la "fe total en Cristo" y el punto de partida metodológico es el "Jesús histórico", la práctica actual de pro-seguimiento de Cristo no solo constituye una exigencia ética de Jesús de Nazaret, sino también un principio epistemológico de conocimiento de la praxis y de la persona de Jesús. Si la praxis de Jesús representa objetivamente la mejor mystagogia para el Cristo de la fe, la práctica actual del seguimiento suyo permite subjetivamente achicar la distancia histórica con Jesús de Nazaret y reconocerle como el Cristo (57). En la medida que este seguimiento arraiga en la realidad de los pobres, tiene lugar una auténtica "ruptura epistemológica" (58), cuya justificación queda entregada ulteriormente a una experiencia del círculo hermenéutico que Jon Sobrino resume en los siguientes términos: "desde los pobres se piensa que se conoce mejor a Cristo, y ese Cristo mejor conocido es el que se piensa que remite al lugar de los pobres" (59).

\section{b) La emancipación como principio hermenéutico en E. Schüssler Fiorenza}

En el caso de E. Schüssler Fiorenza, es aún más claro que en Jon Sobrino que el principio hermenéutico de la Escritura se halla fuera de esta. La Biblia no se explica por sí misma. Esta autora saca la hermenéutica bíblica de su quicio tradicional, exigiendo de la metodología científica considerar la emancipación social, cultural y religiosa de las mujeres como su principio hermenéutico decisivo.

E. Schüssler Fiorenza navega entre los dos extremos posibles de la hermenéutica postmoderna. Critica la interpretación fundamentalista de la Biblia camuflada de cientificidad, puesto que "con una lectura dogmática literal, las cristologías fundamentalistas intentan 'fijar' las expresiones pluriformes de las Escrituras y tradiciones cristianas, en particular las ambiguas metáforas y los variados textos que tienen que ver con Jesucristo. Tras ello intentan consolidarlos en un discurso masculino de sentido único, definitivo y unívoco" (60). Tampoco acepta fácilmente los estudios bíblicos feministas de la academia: "los análisis literarios feministas de los Evangelios o las historias de Jesús que adoptan estrategias positivistas del estudio de la Biblia no interrumpen, sino que contribuyen al fundamentalismo autoritario" (61).

Por otra parte, ella es muy consciente del error en que suelen incurrir las teologías feministas de liberación que, en respuesta a esta hermenéutica fundamentalista masculina, absolutizan el valor de la hermenéutica contextual. Dice: "los

(55) JL., p. 79.

(56) JL., p. 80.

(57) Cf. JL., p. 82.

(58) Cf. JL., p. 57.

(59) JL., p. 56.

(60) CFC., p. 25.

(61) CFC., p. 26. 
discursos que defienden el 'regionalismo' cristológico, a su vez, tienden a servir los intereses del pluralismo liberal" (62). Si no es posible una sola lectura de un texto, tampoco es suficiente relativizar la investigación de Jesús a través de interpretaciones privadas y plurales. "Los estudios escritos desde un punto de vista confesadamente 'étnico' y local -tales como las articulaciones de la cristología feminista europea 'blanca', australiana, norteamericana, afroamericana, asiática, africana o latinoamericana- también corren el peligro de ser cooptados por la postmodernidad" (63). En la medida que estas cristologías procuran mejorar la condición de las mujeres a través de una interpretación de los textos que dispute a los hombres el poder, no son capaces de superar las estructuras dualistas de clase, raza, género, religión, nación y edad, que han asegurado la dominación de los hombres sobre las mujeres y que, en la medida que persistan, perjudican a mujeres y hombres por igual. Las cristologías "se transforman en el reverso de las lecturas masculinomayoritarias y se tornan 'regionales' siempre que se presentan como articulaciones exclusivas que pertenecen solo a un grupo étnico particular" (64).

E. Schüssler Fiorenza supera el relativismo y el fundamentalismo hermenéuticos en la medida que halla fuera de la Escritura el criterio epistemológico de su lectura, aun cuando la misma Escritura funde remotamente tal criterio, a saber, el de la emancipación de las mujeres y el de todos en general. El interés por la liberación efectiva, producto de una praxis determinada e inspirada bíblicamente, constituye para esta autora el criterio ulterior de la interpretación de la Escritura y no un texto particular suyo que, como "dato" fundamental, pudiera iluminar su lectura o hacer de principio metodológico clave. En sus propias palabras, "la meta de una hermenéutica feminista de la liberación no es simplemente la colección y sistematización de materiales cristológicos cristianos antiguos como 'datos' para la reflexión teológica sistemática a favor de la formación de identidad cristiana. Antes bien, apunta a una reconceptualización de los discursos bíblicos cristológicos y las construcciones de identidad cristiana en pro de la praxis emancipadora" (65).

Es un interés actual, es la necesidad hodierna de liberación universal, lo que debiera impulsar cualquier hermenéutica cristiana y no la Escritura en cuanto tal, puesto que esta se ha prestado a menudo para la opresión de las mujeres. La potencialidad liberadora de la Escritura solo es actualizada cuando sus criterios de interpretación no obtienen su validación de los procedimientos metodológicos de la dogmática, sino del interés del intérprete por la emancipación. Es este interés el que puede descubrir los criterios teológicos "en el potencial encarnado que tienen los textos y marcos intelectuales para engendrar procesos de interpretación y praxis que pueden transformar mentalidades kyriocéntricas y estructuras de dominación" (66). E. Schüssler Fiorenza no deja espacio ni al fundamentalismo ni al relativismo, al fijar a la hermenéutica bíblica una finalidad histórica, concreta y abierta a la universalidad: "este interés teológico en la liberación de todas las mujer*s debe determinar

(62) CFC., p. 26.

(63) CFC., p. 26.

(64) CFC., p. 26.

(65) CFC., p. 95.

(66) CFC., p. 96. 
todos los marcos intelectuales de estudios bíblicos en particular y de estudios cristológicos en general, y no simplemente los de los estudios feministas" (67).

Para abrir paso a su postura hermenéutica, E. Schüssler Fiorenza emprende un agudo ataque contra las metodologías que quieren hacernos creer que están libres de intereses exógenos que pudieran distorsionar la interpretación de la Escritura. Al efecto, desenmascara los intereses no confesados de la hermenéutica bíblica actual: "los discursos bíblicos eruditos construyen y propagan la identidad cristiana y occidental no solamente como un 'hecho dado' canónico-teológico o clásico natural, determinado masculinamente y válido universalmente, sino también como una identidad kyriarcal preconstruida que se ha tornado el 'sentido común' cultural y religioso. En la medida en que los biblistas intentan construir discursos cristológicos, tienen como objetivo mantener la identidad cultural occidental y religiosa cristiana como identidad kyriarcal preconstruida, y elaborar estas formaciones de identidad en términos doctrinales-históricos, espirituales-imaginativos o histórico-apologéticos" $(68)$.

Sobre la justicia de este ataque no toca hacerse cargo, pues lo que aquí importa es reconocer la originalidad que representa la ubicación del principio clave de la hermenéutica bíblica en los intereses extrabíblicos y actuales que debieran configurarla. ¿Cómo es posible juzgar que estos intereses sean legítimos? Por más que se afirme la necesidad de una circularidad hermenéutica entre "texto" y "contexto" que supere la posibilidad de una interpretación caprichosa, en el caso de esta cristología feminista crítica el círculo deja de ser vicioso solo en la medida que se rompe a favor de una praxis de liberación universal que no puede verificarse sino a posteriori. Pero, teóricamente, E. Schüssler Fiorenza enuncia al menos el camino que conduce de la particularidad a la universalidad de la liberación.

El caso es que esta teóloga emprende una lucha en todas las direcciones que le parecen necesarias: contra los sistemas de opresión sociales y políticos, y contra el "sentido común" y las culturas que incorporan y reproducen marcos ocultos de dominación. Pero lo que más llama la atención de su metodología no es solo que combate la hermenéutica bíblica contemporánea aunque lleve el título de feminista, sino que somete a la misma Escritura a una severa deconstrucción. El análisis de las Escrituras es crítico no solo en contra de la manida neutralidad metodológica científica, sino porque cuestiona el uso que ha podido hacerse de ella en perjuicio de las mujeres. Presidido por un interés liberacionista, el análisis crítico de las Escrituras "tiene ramificaciones positivas para la autocomprensión y la teología cristianas, en la medida en que deconstruye, en pro de la praxis emancipadora, los textos kyriocéntricos y las lecturas cristológicas positivistas del Testamento Cristiano que perpetúan una formación de identidad cristiana kyriarcal" (69). Buscando reconstruir su sentido liberador sepultado, la teología crítica de E. Schüssler Fiorenza debe primero desmantelar la retórica teológica que, aun en la Escritura, no ha sido sino producción histórica kyriarcal. El "lenguaje masculino absolutizado y fosilizado acerca de D**s y Cristo", según sus palabras, debe ser "cuestionado y socavado radicalmente"

(67) CFC., p. 96.

(68) CFC., p. 109.

(69) CFC., p. 95. 
(70). En particular, la hermenéutica feminista crítica denuncia las "naturalizaciones" y las "teologizaciones" de las diferencias de sexo/género, que la Escritura y la tradición han favorecido toda vez que ellas "participan en un proceso lingüísticosimbólico de 'naturalización' del género gramatical. No solo el lenguaje religioso, sino también el lenguaje androcéntrico en general reinserta reiteradamente los prejuicios culturales-religiosos y las relaciones sociales-kyriarcales que a su vez apoyan sus prácticas disciplinares" (71). Solo de una práctica feminista crítica que impulse una clasificación y evaluación de los rastros de la cristología bíblica emancipadora, se puede esperar una "liberación y bienestar que todavía no hayan sido realizadas plenamente en la historia" (72).

La hermenéutica bíblica de esta cristología desmantela las articulaciones kyriarcales que durante el período de elaboración de la Escritura han sido reproducidas en ella para asegurar la "subordinación de las mujeres y esposas nacidas en libertad, de esclavas y esclavos, de los jóvenes y de la comunidad cristiana como un todo al amo/señor/padre/emperador" (73), que la erudición bíblica ha demostrado que no provienen de la teología cristiana, sino del contacto del cristianismo primitivo con la cultura grecorromana. La empresa de deconstrucción de E. Schüssler Fiorenza se extiende además a la génesis del dogma cristológico. La unidad de la Iglesia, vista como condición de la unidad del imperio, habría obligado a Constantino y a los sucesivos emperadores a uniformar la interpretación de la Escritura (74).

En definitiva, el esfuerzo de deconstrucción tiene por objeto una reconstrucción, "la reconstrucción del movimiento de Jesús como movimiento emancipador de basileia” (75). E. Schüssler Fiorenza injerta el movimiento de emancipación femenino en el movimiento de Jesús en pos de aquella basileia que en los primeros tiempos del cristianismo representó un desafío para el imperio romano. De aquí que al momento de abordar el estudio de Jesús, la autora no se centre en su carácter de varón ni particularmente en su relación con las mujeres -lo que reiteradamente hacen las cristologías feministas-, sino en su proyecto liberador. Para ella, "una identidad cristiana feminista debe articularse reiteradamente dentro de las diversas luchas emancipadoras por la visión de la basileia/la comunidad de naciones de $\mathrm{D} * * \mathrm{~s}$ que significa bienestar y libertad para todos los habitantes de la aldea global" (76).

\section{AL TERMINAR: LA CUESTIÓN CATÓLICA EN LAS TEOLOGÍAS CONTEX- TUALES DE LIBERACIÓN}

Al terminar centramos la atención en el punto probablemente más complejo, aunque mencionado solo a la pasada en lo que se ha venido planteando. El carácter

(70) CFC., p. 227.

(71) CFC., pp. 67-68.

(72) CFC., p. 227.

(73) CFC., p. 33.

(74) Para esta autora, "la promulgación calcedónica de la doctrina de la encarnación es un buen ejemplo de cómo el kyriocentrismo y el kyriarcado se alimentan y se refuerzan mutuamente" (CFC., p. 41).

(75) CFC., p. 139.

(76) CFC., pp. 129-130. 
católico de las teologías de los autores estudiados hace en su caso aún más apremiante la exigencia interna de cualquier teología cristiana, desde el Nuevo Testamento hasta nuestros días, de interpretar eclesialmente la revelación. Aunque la hermenéutica magisterial católica sea también ella por fuerza contextual, su función no es sectorial. La labor interpretativa magisterial no debiera entrar en disputa de igual a igual entre las múltiples interpretaciones locales, pues a ella incumbe como responsabilidad primera la unidad de la Iglesia. Pues bien, empresas hermenéuticas como las de Sobrino y Schüssler Fiorenza, al reclamar legítimamente la posibilidad de una interpretación de sus respectivas praxis, no pueden desentenderse de la interpretación obligante del magisterio eclesiástico. Puesto que en las obras vistas esta preocupación no existe, la señalamos aquí directamente. A modo de ejemplo recordamos que el Nuevo Testamento admitió diversas cristologías en la medida que la Iglesia confesó a uno y al mismo Jesucristo.

Por otra parte, acogido el aporte de teologías contextuales de liberación como estas, no hay vuelta atrás. El servicio a la unidad de la pluralidad correspondiente al magisterio no podrá apoyarse más en un acceso inmediato a la revelación. No existe un punto para interpretar privilegiado y libre, a su vez, de ser interpretado. En la medida que la hermenéutica ha sido acogida por la teología, la pretensión de poseer "el" sentido de la revelación es visto como una desmesura ideológica, funcional a un abuso del poder que cada vez menos católicos están dispuestos a soportar.

En otras palabras, el problema hermenéutico último para una teología que quiere ser católica, no parece ser la superación del fundacionalismo y del relativismo, sino el de la posibilidad de una pluralidad de interpretaciones encaminadas a la comunión y el de una interpretación común facilitadora de interpretaciones personales y sectoriales. Esta permitiría superar la Babilonia postmoderna, la de la tolerancia de múltiples interpretaciones dispares que tarde o temprano conducen al individualismo y al conflicto. Aquella, es demandada tanto por la necesidad de liberaciones sectoriales como por el reclamo de creyentes que legítimamente quieren ser cada uno un "intérprete de Cristo".

Entre cristianos el gran signo de los tiempos es el "libre examen". En nuestro campo abunda el "católico a mi manera". Miradas las cosas a fondo, lo que entre católicos pudiera constituir un acto de desobediencia o desacato, desde un punto de vista teológico no deja de tener un fundamento inconmovible e irreductible: la libertad de los hijos de Dios, el deber de obedecer solo a Dios y en conciencia. Hablamos de un dato central de la salvación cristiana. La comprensión trinitaria de la revelación tiene como origen último la obediencia libre y personal del creyente al Padre por el Hijo en el Espíritu y que, en negativo, dice: "nadie puede interpretar por mí".

Esto no obstante, el católico sabe que la jerarquía de la Iglesia tiene autoridad para "interpretar por otros". Pues bien, la mala articulación de ambos polos de esta hermenéutica conduce de hecho al más hondo conflicto de las interpretaciones en el campo católico. En la medida que la interpretación personal y la eclesial compitan en el mismo plano una contra otra, la inclinación moderna empujará a los sujetos a que dejen la Iglesia y la actitud del pícaro latinoamericano que rezará más o menos así: "ustedes hacen como que mandan y nosotros hacemos como que obedecemos". Pero cabe también la solución católica auténtica de acuerdo a la cual la interpreta- 
ción personal y la eclesial compitan una con la otra, y no una contra la otra. Lo cual solo será posible cuando compitan en planos distintos, pero complementarios.

Las teologías contextuales de liberación que hemos examinado aquí no incursionan en esta materia y, por lo mismo, no resuelven el problema que representan. Si para estas teologías aquello que hay que interpretar es la praxis de liberación, su tarea católica pendiente es explicar cómo el primado de la consecución efectiva de la liberación no desquicia la comunión eclesial ni hace superfluo el magisterio que custodia la unidad de la Iglesia. Por el contrario, queda pendiente para el magisterio el ejercicio de un modo de interpretar la revelación que abandone los dogmatismos prehermenéuticos, para acompañar las búsquedas prácticas y plurales de liberación personales y sectoriales, compartiendo su oscuridad en la fe, animando sus frustraciones con la esperanza evangélica y corrigiéndolas con la caridad de quien tiene autoridad porque antes de interpretar "para los otros" no cesa de "interpretar para sí y con los otros".

\title{
RESUMEN
}

Las teologías contextuales se han beneficiado del desarrollo de la filosofía hermenéutica $y$, al hacerlo, han obligado a toda teología a explicitar para qué se interpreta, quién interpreta, qué se interpreta y cómo se interpreta. El presente artículo se aboca a responder estas preguntas en los casos de la cristología de Jon Sobrino y la de Elizabeth Schüssler Fiorenza. En la conclusión recoge la aporía que estos planteamientos representan para la teología católica en la medida que invocan el valor del contexto, pero no siempre haciéndose cargo del valor de la unidad de la teología y de la Iglesia.

\begin{abstract}
Contextual theologies have greatly benefited from the development of hermeneutic philosophy. However, this has also forced all theological thought to spell out: why interpret, who interprets, what is to be interpreted and how things are interpreted. The article attempts to answer these questions in the light of the theologies of Jon Sobrino and Elizabeth Schüssler Fiorenza. In conclusion, the author highlights the intellectual difficulties these contributions entail for the Catholic theology, to the extent that they appeal to value of the context; without a full awareness of the value of the unity of the theology and the Church.
\end{abstract}

